ASEAN Journal of Science and
JURNAL UPI

\title{
Predictors of Polio Immunization Hesitancy: A Cross- Sectional Study from Mardan Pakistan
}

\author{
Muhammad Ahsan ${ }^{1}$ *, Hassan Raza ${ }^{1}$, Saba Ali ${ }^{1}$, Muhammad Hassan Raza² \\ ${ }^{1}$ Departement of epidemiology and public health, University of Agriculture, Faisalabad Punjab, Pakistan \\ ${ }^{2}$ Department of Biotechnology, COMSATS University Islamabad, Abbottabad Campus-Pakistan \\ Correspondence: E-mail: Professor4463@gmail.com
}

\begin{abstract}
A B S T R A C T S
We identified groups most at risk of ambiguity and reluctance to take a polio immunization in Mardan, Pakistan general population. A descriptive ad cross-sectional study was conducted in Mardan to poll 593 Pakistani people on their views regarding polio immunization acceptance. Attitudes and perceptions towards polio immunization acceptance were predicted using logistic regression analysis. Polio immunization acceptance was 55.8\%. There was higher vaccination acceptance among females having children of 5 years of age. People residing in rural areas with illiteracy, socioeconomic vulnerability, and not following the proper guidelines by the Government, concerning the safety of vaccine, suffered from food insecurity, and unemployed condition are less likely to accept the polio vaccination than participants who were university graduates, believe in healthcare agencies, residing in urban areas. Adopting polio immunization was also less probable among individuals who thought there was a conspiracy behind them. These measures should include restoring public confidence in national health authorities and organized awareness efforts that provide clear information regarding vaccination safety, effectiveness, and manufacturing.
\end{abstract}




\section{INTRODUCTION}

Poliomyelitis (polio) is a viral illness extremely infectious caused by polio. It is a significant issue in vast parts of the developing globe that continually threatens children with important social and economic development concerns like covid (Anwar et al., 2020; Fetene \& Sherani, 2013). The illness has a global significance for public health because it is the major leading cause of disability among children of age five 5 . There were 3 strains of poliovirus were found worldwide, out of these three wild polioviruses (WPV) types 2 were successfully eradicated from the world while type 1 and type 3 remain mostly in endemic polio regions, and it is not linked with blood groups like covid polio may cause paralysis which may be a partial or complete, acute respiratory syndrome or sometimes leads to mortality. It could be asymptomatic, spread through personal contact (Infected nose and mouth secretions) and contaminated faces (Suresh et al., 2018), due to which precautions are necessary incidence of polio was widespread globally during the pre-vaccine period (Asif et al., 2020). However, after the introduction in the 1955's of inactivated polio vaccine (IPV) and the 1960s of live oral polio vaccine (OPV), in the United States, the last case of polio linked with Wild Poliovirus (WPV) was discovered quickly in 1991. The number of countries suffering from polio-endemic was lowered from 125 to 3 in 1988 Just after the Global polio eradication initiative (GPEI) was launched. These three countries included Nigeria, Pakistan, and Afghanistan where polio is still prevalent. In 2014, globally 359 WPV cases were recorded, 306 of them were in Pakistan. Despite the frightening figures, Pakistan has significantly improved polio eradication as more than 20,000 cases decreased in the early 1990s to 306 in 2014 (Obregón et al., 2009). However, the nation has significant difficulties that must be addressed to eliminate polio. In Pakistan, a number of reasons have jeopardized attempts to eliminate polio include poor administration of programming, parental rejection, and resistance to local vaccination (Hillman \& Latimer, 2017). It has been stated that, in March 2015, 34.7 million children were vaccinated for polio, 33.6 million of them (97\%) and that the others were missing primarily owing to security $(2 \%)$ and parental rejection (1\%). However, two nations, including Pakistan and Afghanistan, remain classified as polio-endemic (Fetene \& Sherani, 2013).

This is a worrisome scenario since the current polio epidemic struck all of the regions in Pakistan where the total number of cases sharply increased in northern areas of Pakistan and Baluchistan. In KPK, the Peshawar division is the region that is most afflicted by the illness (37 out of 68). The highest number of cases recorded in Baluchistan were those of the Quetta Division (19 out of 23) (Chandir et al., 2020). Mass polio immunization efforts began in April 1994 in Pakistan and continue (Alexander et al., 2014). Rigorous efforts to stop the fast spread of polioviruses in Pakistan have been adopted in conjunction with national immunization days (NIDs) in the form of a complementary vaccination round. Pakistan uses trivalent oral polio (OPV) at birth, and 6,10, and 14 weeks of age. In their routine vaccination programmed (Mushtaq et al., 2010). The efficacy of polio vaccination in Pakistan is a significant issue. With an average of 8 hours of power interruptions per day owing to load-shedding, the preservation of the cold chain may pose an issue for polio storage (Sanders et al., 2016). However, logistical obstacles, particularly in conflict regions; managerial problems; unclear financing; political tension; persistent anti-vaccine rumors, and opposition to the work of polio eradication (Orr et al., 2016) have arisen. In the meantime, public acceptability of vaccinations is still essential. Negative polio communication in Nigeria led to a reduction in the uptake of vaccinations in five northern Nigerian states. negative attitudes and hesitancy towards vaccination acceptance are due to the rumors of religious scholars and political parties who considered it an American plot to make the local people infectious and infectious.

DOI: http://dx.doi.org/10.17509/xxxx.xxxx p- ISSN 2775-6793 e- ISSN 2775-6815 
The boycott of polio in Nigeria has proven to be a major failurec, as cases have risen from 202 in 2002 to 1143 in 2006 (Ghinai et al., 2013). Another source of public health concern was political motivation as revealed by a boycott of polio immunization in northern Nigeria, where disregarded groups have been organized to oppose government-led initiatives (Larson \& Ghinai, 2011).

Despite strenuous efforts to stop fast polio transmission in Pakistan, success is far from achievable. The development of the 'End Polio from Pakistan' campaign was seriously hindered by safety hazards to health-care personnel, erroneous religious and cultural beliefs, and restricted access to difficult communities. Some researchers have made many attempts to identify obstacles to polio vaccination in affected areas in Pakistan. Researchers from the Hazara Region have identified a lack of awareness and misunderstandings regarding polio vaccination as significant barriers. Another Peshawar research showed an unsatisfactory understanding of polio immunization among participants. The research was nevertheless confined to urban areas on the campus of Peshawar University (Naeem et al., 2012).

There were misconceptions of parents, safety concerns, lack of Confidence in healthcare authorities towards polio immunization in high conflict regions in Pakistan as revealed by UNICEF and Harvard research program. Periodic assessment of knowledge and behavior in a population provides the foundation for educational diagnostics and measures to change attitudes and behavior throughout time. Evaluation of participants' knowledge and attitudes about polio could pave the way for data-driven interventions to support GPEI. The research was aimed to access the knowledge, awareness, and attitudes towards polio immunization and its predictor among the general public of Mardan, KP, Pakistan.

\section{METHODS}

\subsection{Study Design}

A descriptive, cross-sectional study was conducted in Mardan divisions in Pakistan for 3 months from February 2021 to May 2021. Although Mardan reports a high number of cases of polio in 2014, safety concerns and a prohibition against polio vaccination by the rumors preclude the authorization was included in this research (Khan et al., 2015). The study is reported according to the STROBE observational research guidelines (Vandenbroucke et al., 2007). In light of the high number of reported polio cases in these regions, this research was carried out in Mardan. Multi-stage sampling techniques are used to take from division a random sample. First, two districts were randomly chosen from Mardan. Second, two tehsils were chosen randomly from the district selected. Third, two union councils were randomly chosen from each of the tehsils selected. The questionnaire was given in the relevant union councils to the participants in locations of mutual interest (shopping, basic healthcare units, utility shops, restaurants, etc.). These sites have been chosen for data collecting because of the socioeconomic diversity of the population. Rural and urban areas were classified by population census in 1981 and 1998. Researchers apply the same categorization in epidemiological investigations elsewhere (Khowaja et al., 2012). The data collectors have spent an average of 5 hours at every site at a random time of the day. In 5 hours, individuals were contacted randomly and asked to take part in the survey. For the collection of participants' data, a self-administered questionnaire was utilized. However, in instances where participants could not complete the questionnaire due to literacy problems, interviewer-assisted approaches for data collection were employed. 


\subsection{Calculation of Sample Size and Eligibility Criterion}

The sample size was determined using Raosoft software, with a power distribution of $80 \%$ by $50 \%$, and a confidence interval and an error range of $95 \%$ by $5 \%$ correspondingly. From each division, a sample size of 593 individuals was produced. Eligibility for this research was assessed for all those residing in target areas, above 18 years of old, have no physical disability, and are not related to the medical background for reducing the research bias.

\subsection{Instrumentation of Study}

After an extensive literature study of the associated published studies. A questionnaire was developed. After the initial version was drawn out, the questionnaire was subordinated by a panel of five experts including two infectious disease management specialists, one pharmacist, one public health analyst, and a sociologist. The proposed changes to the questionnaire were made before they were sent to a small sample of 20 people ( 10 from each division) for facial validity. In light of other available material, the changes suggested by the participants of the questionnaire were included the questionnaire was then translated into Urdu and subsequently translated into English according to conventional questionnaire translation procedures. The study instrument consisted of 21 items, split into three parts. The first section included 7 questions that examined participants' demographic information. Section two, consisting of 8 questions, assessed participants' knowledge and perceptions towards vaccination against polioviruses. Section 3 investigated predictors of vaccine hesitancy.

\subsection{Ethical Approval}

This study was ethically authorized by the University of Agriculture Faisalabad Research Committee. The research was also conducted in accordance with the ethical norm for human experimentation (Sisk et al., 2020). Participants were educated on the research goals and their informed consent before data collection was acquired.

\subsection{Statistical Study}

SPSS Version 25 was utilized to analyze the data. The analysis of the acceptability of vaccinations among the various sociodemographic categories was evaluated utilizing a chisquare test and Fisher's exact test when applicable. Univariate and multivariate tests have been conducted to compare vaccination acceptability with interest variables. If the $p$-value was 0.05 or below, the test result was deemed statistically significant.

\section{RESULTS}

\subsection{Demographics}

A total of 618 individuals attended the study. Of which 593 were complete the questionnaire and analyzed it. The median age of the participants was 43 , and over half (63.4\%) were men. Half of those interviewed $48.8 \%$ were married and having children. Half of the participants had primary school education, $21.8 \%$ had college degrees, and $11.7 \%$ were university graduates. Also, $47.3 \%$ of people were employed, and just $27 \%$ stated that they had suffered from chronic diseases.

Participants stated that they had polio suffered patients in their social circle. As well due to socio-economic vulnerability and high employment rates half of the participants suffered from food insecurity. As shown in Table.1 more than half (52.4\%) of participants trusted religious scholars (Imam, Sheikhs, Muftis) for information about polio vaccines. $32.2 \%$ of 
Participants trusted healthcare providers and $14.3 \%$ trusted Government agencies as a reliable source of information about polio vaccines.

Participants stated that they had polio suffered patients in their social circle. As well due to socio-economic vulnerability and high employment rates half of the participants suffered from food insecurity. As shown in Table 1, more than half (52.4\%) of participants trusted religious scholars (Imam, Sheikhs, Muftis) for information about polio vaccines. $32.2 \%$ of Participants trusted healthcare providers and $14.3 \%$ trusted Government agencies as a reliable source of information about polio vaccines.

Table 1. Socio-demographic characteristics of study participants.

\begin{tabular}{|c|c|}
\hline Variable & $\mathbf{N}(\%)$ \\
\hline \multicolumn{2}{|l|}{ Age (years) } \\
\hline Median $[\mathrm{IQR}]$ & $43[21-52]$ \\
\hline $18-30$ years & $321(54.1)$ \\
\hline $31-45$ years & $167(28.1)$ \\
\hline$>45$ years & $105(17.8)$ \\
\hline \multicolumn{2}{|l|}{ Gender } \\
\hline Male & $376(63.4)$ \\
\hline Female & $217(36.6)$ \\
\hline \multicolumn{2}{|l|}{ Marital status } \\
\hline Married & 289(48.8) \\
\hline Single & $270(45.6)$ \\
\hline Others (Common-law marriage or Divorced) & $34(5.8)$ \\
\hline \multicolumn{2}{|l|}{ Having children } \\
\hline No & 291(49.0) \\
\hline Yes & $302(51.0)$ \\
\hline \multicolumn{2}{|l|}{ Education (Degree) } \\
\hline Primary School education & $298(50.0)$ \\
\hline $\begin{array}{l}\text { High School } \\
\text { College } \\
\text { University }\end{array}$ & $\begin{array}{c}97(16.3) \\
129(21.8) \\
69(11.7)\end{array}$ \\
\hline \multicolumn{2}{|l|}{ Food insecurity } \\
\hline No/ Secure & $208(35.0)$ \\
\hline Minimal & $270(45.6)$ \\
\hline High & $43(7.3)$ \\
\hline Mild & $72(12.1)$ \\
\hline \multicolumn{2}{|l|}{ Employment } \\
\hline Yes & 281(47.3) \\
\hline No & $312(52.7)$ \\
\hline \multicolumn{2}{|l|}{ Get benefits From Government } \\
\hline Yes & 193(32.6) \\
\hline No & 400(67.4) \\
\hline \multicolumn{2}{|c|}{ Not Trusted any source of information regarding polio immunization } \\
\hline No & $314(53.0)$ \\
\hline yes & 197(33.2) \\
\hline Uncertain & $82(13.9)$ \\
\hline \multicolumn{2}{|l|}{ Suffered from Chronic disease Any } \\
\hline No & $433(73.0)$ \\
\hline Yes & $160(27.0)$ \\
\hline \multicolumn{2}{|l|}{ Know any person who suffered from polio } \\
\hline Myself & $2(0.3)$ \\
\hline A family member & $4(0.6)$ \\
\hline A friend & $12(2.0)$ \\
\hline
\end{tabular}


Table 1 (continue). Socio-demographic characteristics of study participants.

\begin{tabular}{lc}
\hline \multicolumn{1}{c}{ Variable } & $\mathbf{N}(\%)$ \\
\hline Colleague & $00(0.0)$ \\
A neighbor & $13(2.1)$ \\
No one & $562(94.8)$ \\
source of information regarding polio immunization & \\
Religious scholars & $311(52.4)$ \\
Healthcare providers & $197(33.2)$ \\
Government agencies & $85(14.3)$ \\
\hline
\end{tabular}

\subsection{Polio Vaccinations Acceptance}

Only $55.8 \%$ of people showed their positive behavior towards polio vaccination acceptance among the general population of Mardan, KP, Pakistan. 32.2\% rejected polio vaccination while $12 \%$ were uncertain regarding polio vaccination acceptance. The Multivariate analysis showed the independent predictors of vaccination acceptance. Polio vaccination acceptance among the general public in Pakistan was average $55.8 \%$. Which is an alarming situation in ameliorating polio-endemic from Pakistan hence this issue should be addressed. Participants who had children are more likely to show their interest in polio vaccination acceptance. A similar pattern emerged among individuals who thought vaccinations are usually safe (OR = $8.943, \mathrm{Cl} 95 \%=6.072-14.792, \mathrm{p}<.001)$ In contrast, individuals over 45 (OR $=0.763, \mathrm{Cl} 95 \%=$ $0.443-0.832, \mathrm{p}<.001)$, and those unemployed ( $\mathrm{OR}=0.568, \mathrm{Cl} 95 \%=0.432-0.831 \mathrm{p}<.001)$, were less likely to accept the Polio vaccine. As well participants suffered from food insecurity were show their negative behaviour towards polio vaccination acceptance $((O R=20.317, \mathrm{Cl}$ $95 \%=13.775-27.083, p<.001)$ Adoption polio vaccinations were also less probable among individuals who thought that polio-endemic is a result of conspiracy behind $(\mathrm{OR}=0.568 ; \mathrm{Cl}$ $95 \%=0.432-0.811, p<.001)$. Multivariate analysis showed that there was higher vaccination acceptance among females. People residing in rural areas with illiteracy, socioeconomic vulnerability, food insecurity, and not following the proper guidelines by the Government are less likely to accept the polio vaccination compared to people with better socioeconomic status and literacy. Participants are afraid that the polio-endemic is the result of a conspiracy as shown in Table $\mathbf{2}$ stated predictors of polio vaccination acceptance.

Table 2. Multivariate analysis of the determinants of Polio vaccination acceptance.

\begin{tabular}{|c|c|c|c|}
\hline Variables & OR & $95 \% \mathrm{Cl}$ & P-value \\
\hline \multicolumn{4}{|l|}{ Age } \\
\hline $18-25$ years & [reference] & & \\
\hline $26-45$ years & 0.961 & $0.943-1.464$ & 0.143 \\
\hline$>45$ years & 0.763 & $0.443-0.832$ & $<.001$ \\
\hline \multicolumn{4}{|l|}{ Gender } \\
\hline Male & [reference] & & $<.001$ \\
\hline Female & 2.233 & $1.749-3.643$ & \\
\hline \multicolumn{4}{|l|}{ Marital status } \\
\hline Single & [reference] & & \\
\hline Married & 1.761 & $1.213-3.112$ & \\
\hline Divorced & 0.747 & & \\
\hline \multicolumn{4}{|l|}{ Having children } \\
\hline Yes & [reference] & & \\
\hline No & 0.385 & $0.371-4.591$ & \\
\hline
\end{tabular}


Table 2 (continue). Multivariate analysis of the determinants of Polio vaccination acceptance.

\begin{tabular}{lccc}
\hline \multicolumn{1}{c}{ Variables } & OR & 95\% Cl & P-value \\
\hline Employed & & & \\
Yes & [reference] & & \\
No & 0.512 & $0.567-0.802$ & \\
Polio immunization may pose serious health effects & & & \\
No & [reference] & & \\
Yes & 3.098 & $2.794-4.062$ & \\
Vaccines are safe & & & \\
No & [reference] & & $<.001$ \\
Not sure & 3.754 & $2.167-5.751$ & $<.001$ \\
Yes & 8.943 & $6.072-14.792$ & $<.001$ \\
Afraid that polio-endemic is the result of a & & & \\
conspiracy & & & $=.002$ \\
No & [reference] & & \\
Yes & 0.568 & $0.432-0.831$ & \\
Distrust any source of information & & & \\
No & [reference] & & \\
Yes & 0.294 & $0.169-0.502$ & \\
Food insecurity & & & \\
Secure & [reference] & & \\
Not sure & 4.247 & $3.022-5.024$ & $<.001$ \\
Yes & 20.317 & $13.775-27.083$ & $<.001$ \\
& Odds Ratio & Confidence Interval & \\
\hline
\end{tabular}

\subsection{Perception and Concerns Regarding Polio Vaccines}

Half of the participants stated that Polio immunization is important for a child's health. People are more concerned regarding vaccine safety, availability, and accessibility. Half participants (50.8\%) revealed that they are more concerned regarding the availability, difficulty in distribution of vaccines across the country. The same pattern emerged regarding the safety of vaccines $48.8 \%$ participants believed that all vaccination program is effective in the eradication of viral diseases as well $50 \%$ stated that rumors against vaccination as it could pose some serious health effects are the major public health concerns. 39\% stated that they do not need any vaccination for common diseases. One-third of the participants were confident about government steps towards polio eradication (see Table 3).

Table 3. Perception towards polio vaccination and vaccine concerns.

\begin{tabular}{lccc}
\hline \multicolumn{1}{c}{ Perceptions } & Agree & Uncertain & Disagree \\
\hline & $\mathbf{( \% )}$ & $\mathbf{N ~ ( \% )}$ & $\mathbf{N ~ ( \% )}$ \\
Polio immunization is important for a child's health. & $311(52.4)$ & $81(13.7)$ & $201(33.9)$ \\
All vaccination programs for the child are important. & $289(48.8)$ & $78(13.1)$ & $226(38.1)$ \\
Confident about Government officials in polio eradication. & $201(33.9)$ & $67(11.2)$ & $325(54.9)$ \\
Side effects are great hinder in getting polio vaccination. & $298(50.0)$ & $101(17.0)$ & $194(32.8)$ \\
There is a difficulty in the distribution of vaccines across the & $301(50.8)$ & $93(15.7)$ & $199(33.6)$ \\
country. & & & \\
$\begin{array}{l}\text { The child does not need any vaccination for common } \\
\text { diseases. }\end{array}$ & $231(39.0)$ & $78(13.1)$ & $284(47.9)$ \\
Concerned about serious health effects of the vaccine. & $301(50.8)$ & $69(11.6)$ & $223(38.8)$ \\
\hline
\end{tabular}




\subsection{Attitudes Towards Polio Vaccination Acceptance}

Half (52.1\%) of participants believed that vaccination is needed to defend against polioendemic. $53 \%$ of participants stated they were hesitant to vaccinate their children. $47 \%$ revealed that distance from the clinic is a major hurdle in vaccine acceptance. Mardan and other tribal areas are much more influenced by their culture, religious scholars, and ruling parties hence one-third of the participants revealed that major predictors of polio immunization refusal in these areas were pressure from these factors. Alone $48 \%$ of participants revealed the interference of religious scholars in their child's polio immunization. More than half $59 \%$ of participants show distrusts in Government officials in releasing information regarding the safety of polio vaccination. $61 \%$ of participants said they should be supported by their religious scholars and political parties in releasing accurate information regarding polio immunization. These participants considered them great influencers of society (see Table 4).

Table 4. Attitudes towards polio vaccination acceptance.

\begin{tabular}{lccc}
\hline \multicolumn{1}{c}{ Attitudes } & Agree & Uncertain & Disagree Green \\
\hline $\begin{array}{l}\text { Polio immunization is important to protect people from } \\
\text { polio. }\end{array}$ & $\mathbf{N}(\%)$ & $\mathbf{N ~ ( \% )}$ & $\mathbf{N ~ ( \% )}$ \\
$\begin{array}{l}\text { Have you ever been hesitated about the vaccination of } \\
\text { your children? }\end{array}$ & $314(53.0)$ & 99(16.7) & 95(16.0) \\
$\begin{array}{l}\text { Distance from the clinic is a major hurdle in vaccine } \\
\text { acceptance. }\end{array}$ & $279(47.0)$ & $87(14.7)$ & $177(29.8)$ \\
$\begin{array}{l}\text { social pressure prevented you from your child's } \\
\text { vaccination. }\end{array}$ & $197(33.2)$ & $103(17.3)$ & 293(35.2) \\
$\begin{array}{l}\text { Religious scholars influenced the most regarding } \\
\text { vaccine acceptance. }\end{array}$ & $288(48.6)$ & $109(18.3)$ & $196(33.0)$ \\
$\begin{array}{l}\text { Concerned about safety, that is not revealed by } \\
\text { Government officials. }\end{array}$ & $351(59.1)$ & $68(11.4)$ & $174(29.3)$ \\
\hline
\end{tabular}

\section{DISCUSSION}

The findings revealed that $55.8 \%$ were aware of the transmission, presence of polioendemic, and polio immunization programs in their regions though there may be a lack of widespread implications in the remaining $32.2 \%$ for lack of knowledge and negative attitudes towards polio and polio immunization. In light of other current research, these findings appear balanced. But people's perceptions and attitudes towards polio immunization were low due to many reasons as religious beliefs, distrust of any source of information from Government and international organizations, much influence from Americans. A lot of people are concerned about the safety of vaccines available. Mass media campaigns combined with planned communication frameworks such as social mobilization may be useful in addressing the problem in distant parts of Pakistan. It is worth mentioning that our research emphasized the important combination of knowledge with the participants' age. Young people seemed to be better informed than elderly people. popular health information with a planned communication framework may develop for adults through social media websites and campaigns to tackle polio-endemic and negative attitudes and perceptions towards polio immunization (Mushtaq et al., 2010). Further research to verify these findings is needed, and the treatments should be revised fittingly. seasonal influenza vaccines were lower than the worldwide norm. 
Binary logistic regression predicted polio vaccinations in this research. The present study found that younger individuals accepted polio vaccinations more readily than older participants. This is explicated by the age distribution of the nations, with Pakistan having a youthful population and high literacy among the young people in the KPK regions. The adoption of polio vaccinations was also less probable among individuals who thought there was a conspiracy behind them, and they showed their concerns towards vaccine safety, availability, and distribution. As well much concerned regarding proper health information framework to reveal the knowledge and awareness regarding its safety. Hence, religious scholars, community leaders, and Government officials are responsible for promoting vaccine adoption as revealed by study participants. Vaccination convenience also relates to the vaccine's availability, cost, distribution, and accessibility. Vaccine complacency is linked to the low perceived risk of vaccine-preventable illness and therefore linked to unfavorable vaccine perceptions. Polio hesitation predictors, including literacy, food security, religious and political obstacles, were examined. As shown in our research, half of the participants regarded religious academics as a confident source of knowledge about the polio vaccine.

The obstacles are connected to religious fanaticism and, at times, to international political objectives. The Pakistani government handled the problem using Social Mobilizers and Religious Leaders and the deployment of Policemen to make the vaccination program smooth. However, the appearance, between January and August 2019, of 53 new cases of polio, more instances than in the last three years, led to demands for more severe restrictions in the years ahead to address the issue (Mushtaq et al., 2010). The reluctance of a significant percentage of the general public to vaccinate their children is one of the worrisome reasons that impede polio immunization. Vaccine adoption was also less common in those groups who thought there was a conspiracy behind it and that they were more worried about the safety of the vaccine. There are two causes for this avoidance. In Pakistan, children get higher doses than the recommended amount by WHO which is increasing public suspicion due to their lack of knowledge of the necessity for increase dosages in tropics (Obregón et al., 2009) In addition, conspiracy rumors abound about the misuse of the vaccinations and the side-effects of the vaccine during storage and shipping. In a single event in 2019, hundreds of youngsters raced to a hospital with stomach problems, vomiting, and fainting, and furious protestors in the Khyber Pakhtunkhwa Province bruised healthcare facilities (Protesters Burn Health Unit in Peshawar over Polio Vaccine. - Google Scholar, n.d.). A major issue in Pakistani culture is that elderly person of family influences the whole family as they are decision-maker and has the power to decide for all social issues including either child will get immunization or not. Results revealed that knowledge and awareness of elderly people in the family is the foremost necessity in ameliorating polio from society. People residing in rural areas with low education, socioeconomic vulnerability, and food insecurity were less likely to accept polio immunization. These results are consistent with previous research reported (Afzal et al., 2021). Social depravity and poor healthcare workers' accessibility mostly reflect such results. Other studies further confirmed this view by reporting a greater immunization rate among individuals with medical and/or vaccine facilities within $12 \mathrm{~km}$ of their home (Fetene \& Sherani, 2013).

A large percentage of individuals had unfavorable views about polio vaccination. Public opinions regarding most assertions linked to attitudes were unfavorable. However, the unfavorable views of respondents concerning the storage of polio vaccinations are worth addressing. Polio vaccines need cold chain management from the production location until vaccinations are administered to the patient. A small temperature change may affect the 
molecular structure of the vaccinations, making them ineffective (Shrivastava et al., 2012) many studies have highlighted the necessity to raise community knowledge of Pakistan's cold chain preservation of polio vaccines (Yakum et al., 2015). Necessary steps should be made to develop comprehensive public education initiatives to educate the public on the key components of the cold chain system. In Pakistan, significant electric load shedding (power outages) is also a barrier in maintaining cold chain polio vaccinations. These variables must be taken into account to develop methods to fight such issues. Efforts should also be made to targeted rural regions, which have a more common unfavorable attitude to the polio vaccine. Several papers highlighted misconceptions and misunderstandings about the polio vaccine as a barrier to higher vaccination rates. The convictions of two distinct kinds; demographic, geopolitical, and religious concerns on the one hand, and misconceptions about the vaccination of a kid on the other. The earlier, which are often mentioned, were typically characterized by rumors of the polio vaccine in literature. Demographic concerns were concentrated on the potential fertility effects of polio vaccines on increasing sterility; geopolitical anxieties were about the genuine motive for vaccines, which at the heart of the vaccine campaign exposed suspicions about the desire to shrink Muslim people as part of a foreign agenda. Analysis of polio resistance among Pashtuns has shown that misperceptions and rumor beliefs reflect the wider political discussion in Pakistan.

The kind of caregivers obtained and the source was also mentioned as an important element in polio vaccination. Customized communications tailored to the local community's requirements have been characterized as an essential approach for the promotion of polio vaccination (Hussain et al., 2014). However, communicating information on the advantages of polio vaccination is not adequate, as many studies have highlighted community members who have not trusted in the vaccine messages (Azira et al., 2013; Owais et al., 2011). The receptiveness to vaccination impacted confidence in government institutions and international entities engaged in polio programs. Repeated polio efforts have helped to create community weariness and hesitation of vaccines (Mangrio et al., 2008). Frustrations over the absence of basic services such as water and sanitation also encouraged distrust in the government of Pakistan and led to the rejection of polio vaccines (Ahmad et al., 1999). The research revealed, in contrast, how good experiences have aided polio vaccination via community engagement (Abimbola et al., 2013). One research emphasized the significance of communication techniques like Sehat Muhafiz (health security) as changing attitudes regarding polio activity and health workers (Orr et al., 2016). Several papers have shown how confidence in vaccinating health care professionals may also encourage confidence and acceptance of services given by these employees, including polio vaccinations. A few types of research showed how caregivers declined to vaccinate their children just partly or fully when health care professionals suffered adverse treatment (Nisar \& Dibley, 2014).

These efforts may involve identifying and providing advice to the leaders/decision-makers of rural regions since they are seen as highly respected persons. This approach may be successful in changing rural people's views promptly. Special changes are necessary to alter people's attitudes together with their understanding of polio to help make the childhood dream of the polio-free world a reality. Religious and societal views seemed to be the biggest obstacle to the disease's full elimination. Local religious radicals in Pakistan's tribal regions have condemned polio as an American attempt to sterilize Muslim populations. Researchers in other published studies also identify similar causes (Ali et al., 2019; Khowaja et al., 2012). In addition, immunization efforts have also suffered from political and religious uncertainty in Pakistan, because polio immunization campaigns have proven to be the favorite target of government and external policy opponents. To evaluate the results regarding religious beliefs,

DOI: $\underline{\text { http://dx.doi.org/10.17509/xxxx.xxxx }}$ p- ISSN 2775-6793 e- ISSN 2775-6815 
we need to grasp Islam's fundamental principles in this area. Saudi Arabia's Grand Muslim scholar has also advocated polio-free worlds. Religious scholars as Imams, Mufti, and Muslim intellectuals may help in the eradication of polio and could ameliorate the negative attitudes and perceptions towards polio. Researchers elsewhere are also supporting this suggestion (Khan et al., 2015). We think that our results are significant from a worldwide viewpoint, particularly in other polio-endemic countries like Afghanistan. Poor information and erroneous religious convictions are significant factors in people's understanding of the illness. These variables are highly likely to lead to misunderstandings and possible behavioral obstacles. Based on our results and other published literature, the transmission of information from confident sources such as community leaders and religious experts may substantially decrease the burden of polio from the nations concerned. In addition, the efficacy of communication methods between healthcare professionals and parents has to be evaluated (Chandir et al., 2020).

The merit of this research is that it focuses on the field in which literature availability is low. Another important aspect of this research is the inclusion of individuals from severely polio-afflicted regions. The findings of this research will assist stakeholders and other health authorities to assess Pakistan's policy success in eradicating polio. Cautions should still be used in interpreting these findings since they may not be widespread throughout the whole nation. The results of this research reflect Pakistan's Quetta and Peshawar divisions, which are unable to account for the wider population of Pakistan. Because participation in this research is optional, the possibility for self-selection by community members who are more worried about polio cannot be ignored. Participants were communicated randomly to fold data, which means that alterations in the population cannot be engaged into consideration. Although this does not imitate the internal cogency of the findings, the overall generalizability of the results may be reduced. The direct association between the results of this study and the high incidence of polio in the study areas was not studied. As a general restriction to a self-administered and interviewed questionnaire, we cannot disregard the participants' propensity to give more socially acceptable answers.

\section{CONCLUSION}

The results of the research revealed a lack of information and unfavorable attitudes about polio vaccination among participants. Religious certainty was the biggest obstacle to polio vaccination. Special efforts should be made to educating people about polio to make polio more acceptable. Interventions should be tailored to target individuals who are more likely to have insufficient understanding and unfavorable attitudes about poliomyelitis.

\section{AUTHORS' NOTE}

The authors declare that there is no conflict of interest regarding the publication of this article. The authors confirmed that the paper was free of plagiarism.

\section{REFERENCES}

Abimbola, S., Malik, A. U. and Mansoor, G. F. (2013). The final push for polio eradication: Addressing the challenge of violence in Afghanistan, Pakistan, and Nigeria. PLoS medicine, 10(10), e1001529. 
Afzal, M. S., Khan, A., Qureshi, U. U. R., Saleem, S., Saqib, M. A. N., Shabbir, R. M. K., Naveed, M., Jabbar, M., Zahoor, S. and Ahmed, H. (2021). Community-based assessment of knowledge, attitude, practices and risk factors regarding covid-19 among pakistanis residents during a recent outbreak: A cross-sectional survey. Journal of Community Health, 46(3), 476-486.

Ahmad, N., Akhtar, T., Roghani, M. T., Ilyas, H. M. and Ahmad, M. (1999). Immunization coverage in three districts of North West Frontier Province (NWFP). Journal-Pakistan Medical Association, 49(12), 301-304.

Alexander, J. P., Zubair, M., Khan, M., Abid, N. and Durry, E. (2014). Progress and peril: Poliomyelitis eradication efforts in Pakistan, 1994-2013. The Journal of infectious diseases, 210(1), S152-S161.

Ali, M., Ahmad, N., Khan, H., Ali, S., Akbar, F. and Hussain, Z. (2019). Polio vaccination controversy in Pakistan. The Lancet, 394(10202), 915-916.

Anwar, S., Sharf, B., Usman, M., Panday, D. and Asif, M. (2020). Organic diet as silent pretreatment strategy to boost immune system against SARS-CoV-2. Alq J Med App Sci, $3(2), 10-25$.

Asif, M. (2020). Coronavirus (COVID-19) Symptoms, Treatment and Recent Medical Challenges to the World: A Review. Journal of Preventive Medicine, 5, 20.

Azira, B., Norhayati, M. N. and Norwati, D. (2013). Knowledge, attitude and adherence to cold chain among general practitioners in Kelantan, Malaysia. International Journal of Collaborative Research on Internal Medicine \& Public Health, 5(3), 157-167.

Chandir, S., Siddiqi, D. A., Mehmood, M., Setayesh, H., Siddique, M., Mirza, A., Soundardjee, R., Kumar Dharma, V., Shah, T., Abdullah, S., Akhter, M. A., Khan, A. A. and Javed Khan, A. (2020). Impact of COVID-19 pandemic response on uptake of routine immunizations in Sindh, Pakistan: An analysis of provincial electronic immunization registry data. Vaccine, 38, 7146-7155.

Fetene, N. W. and Sherani, A. (2013). Determinant factors for implementing polio eradication activities under security compromised settings of Pakistan. J Trop Dis, 2(127), 2.

Ghinai, I., Willott, C., Dadari, I. and Larson, H. J. (2013). Listening to the rumours: what the northern Nigeria polio vaccine boycott can tell us ten years on. Global public health, 8(10), 1138-1150.

Hillman, A. and Latimer, J. (2017). Cultural representations of dementia. PLoS Medicine, 14(3), e1002274.

Hussain, T., Tauseef, A., Bari, A., Rasheed, U. and Hassan, J. A. (2014). Awareness among general population attending Civil Hospital Karachi about risk factors associated with infertility. JPMA. The Journal of the Pakistan Medical Association, 64(6), 725-730.

Khowaja, A. R., Khan, S. A., Nizam, N., Omer, S. B. and Zaidi, A. (2012). Parental perceptions surrounding polio and self-reported non-participation in polio supplementary immunization activities in Karachi, Pakistan: A mixed methods study. Bulletin of the World Health Organization, 90, 822-830. 
Larson, H. J. and Ghinai, I. (2011). Lessons from polio eradication. Nature, 473(7348), 446447.

Mangrio, N. K., Alam, M. M. and Shaikh, B. T. (2008). Is Expanded Programme on Immunization doing enough? Viewpoint of health workers and managers in Sindh, Pakistan. JPMA. The Journal of the Pakistan Medical Association, 58(2), 64.

Mushtaq, M. U., Majrooh, M. A., Ullah, M. Z. S., Akram, J., Siddiqui, A. M., Shad, M. A., Waqas, M., Abdullah, H. M., Ahmad, W., Shahid, U. and Khurshid, U. (2010). Are we doing enough? Evaluation of the Polio Eradication Initiative in a district of Pakistan's Punjab province: A lot quality assurance sampling study. BMC Public Health, 10, 1-10.

Naeem, M., Adil, M., Abbas, S. H., Khan, A., Khan, M. U. and Naz, S. M. (2012). Coverage and causes of non-immunization in national immunization days for polio; A consumer and provider perspective study in Peshawar. Journal of Postgraduate Medical Institute (Peshawar-Pakistan), 26(1), 48-54.

Nisar, Y. B. and Dibley, M. J. (2014). Determinants of neonatal mortality in Pakistan: secondary analysis of Pakistan Demographic and Health Survey 2006-07. BMC Public Health, 14(1), 1-12.

Obregón, R., Chitnis, K., Morry, C., Feek, W., Bates, J., Galway, M. and Ogden, E. (2009). Achieving polio eradication: a review of health communication evidence and lessons learned in India and Pakistan. Bulletin of the World Health Organization, 87, 624-630.

Orr, D., Baram-Tsabari, A. and Landsman, K. (2016). Social media as a platform for healthrelated public debates and discussions: The Polio vaccine on Facebook. Israel Journal of Health Policy Research, 5(1), 1-11.

Owais, A., Hanif, B., Siddiqui, A. R., Agha, A. and Zaidi, A. K. (2011). Does improving maternal knowledge of vaccines impact infant immunization rates; $A$ community-based randomized-controlled trial in Karachi, Pakistan. BMC Public Health, 11, 1-8.

Sanders, B. P., de los Rios Oakes, I., van Hoek, V., Bockstal, V., Kamphuis, T., Uil, T. G. and EdoMatas, D. (2016). Cold-adapted viral attenuation (CAVA): Highly temperature sensitive polioviruses as novel vaccine strains for a next generation inactivated poliovirus vaccine. PLoS Pathogens, 12(3), e1005483.

Shrivastava, A., Gupta, N., Upadhyay, P. and Puliyel, J. (2012). Caution needed in using oral polio vaccine beyond the cold chain: Vaccine vial monitors may be unreliable at high temperatures. The Indian Journal of Medical Research, 135(4), 520.

Sisk, B. A., Mozersky, J., Antes, A. L. and DuBois, J. M. (2020). The "Ought-Is" problem: An implementation science framework for translating ethical norms into practice. American Journal of Bioethics, 20(4), 62-70.

Suresh, S., Forgie, S. and Robinson, J. (2018). Non-polio Enterovirus detection with acute flaccid paralysis: A systematic review. Journal of Medical Virology, 90(1), 3-7.

Vandenbroucke, J. P., Von Elm, E., Altman, D. G., Gøtzsche, P. C., Mulrow, C. D., Pocock, S. J., Poole, C., Schlesselman, J. J. and Egger, M. (2007). Strengthening the reporting of observational studies in epidemiology (STROBE): Explanation and elaboration. PLoS Medicine, 4(10), 1628-1654. 
Yakum, M. N., Ateudjieu, J., Walter, E. A. and Watcho, P. (2015). Vaccine storage and cold chain monitoring in the North West region of Cameroon: A cross sectional study. BMC Research Notes, 8(1), 1-7. 